\title{
¿̇S POSIBLE GARANTIZAR LA LIBERTAD SEXUAL SIN LA REFORMA PENAL? EN DEFENSA DE UNA LEY MENOS «INTEGRAL»
}

Is it possible to guarantee sexual freedom without the criminal reform? In defence of a less "comprehensive" law JOSÉ LUIS RAMÍREZ ORTIZ Magistrado Sección Sexta Audiencia Provincial de Barcelona jose.ramirez@poderjudicial.es

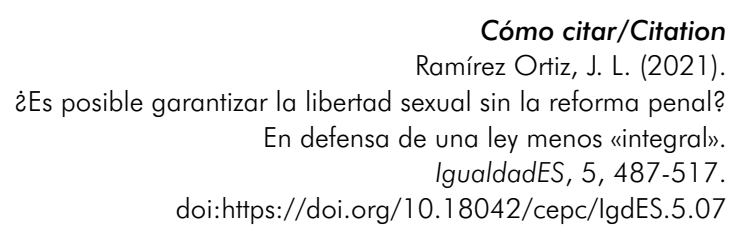

(Recepción: 01/08/2021; aceptación tras revisión: 26/10/2021; publicación: 20/12/2021)

\section{Resumen}

Este trabajo considera innecesaria una reforma estructural de los delitos sexuales desde la perspectiva de género, salvo alguna corrección puntual, entendiendo que la vigente se ajusta al Convenio de Estambul y tiene como eje vertebrador el consentimiento sexual. El artículo llama la atención sobre los riesgos de la legislación integral, que parece convertir la reforma penal en condición indispensable de la articulación de políticas sociales y preventivas, aun cuando tal reforma pudiera no ser necesaria o no serlo en la extensión o dirección propuestos. Concluye que la propuesta no resuelve los problemas de desprotección y revictimización a los que pretende dar solución, pues estos son de orden procesal y probatorio y deberían ser objeto de abordaje específico, y que, por el contrario, supone nuevamente un endurecimiento, aun leve, de un derecho penal sexual sobredimensionado. 


\section{Palabras clave}

Abuso sexual; agresión sexual; consentimiento sexual; delitos contra la libertad sexual; ley integral; prevalimiento; perspectiva de género; revictimización; reforma penal.

\section{Abstract}

This article considers that a structural reform of sexual crimes from a gender perspective is not necesary, except for some specific aspects, as the current Criminal Code is in line with the Istanbul Convention and the consent-based model. The article draws attention to the risks of the "comprehensive law» model, which seems to make criminal reform an indispensable condition for the articulation of social and preventive policies and measures, even though such criminal reform may not be necessary or not in the proposed extension or direction. It concludes that the draft law does not solve the problems of lack of protection and revictimization since these problemas have a procedural and probative nature, and thus should deserve that approach. On the contrary, the draft lawt implies again a hardening, even slight, of an oversized sexual criminal law.

\section{Keywords}

Sexual abuse; sexual assault; sexual consent; crimes against sexual freedom; comprehensive law; undue influence; gender perspective; revictimization; criminal reform. 


\section{SUMARIO}

I. LA FASCINACIÓN POR LA REFORMA PENAL. II. EL PROYECTO DE LEY ORGÁNICA DE GARANTÍA INTEGRAL DE LA LIBERTAD SEXUAL: 1. Lenguajes Y traducciones. 2. La exposición de motivos del Proyecto. 3. Las leyes integrales. 4. Las principales propuestas penales. III. LA PERSPECTIVA DE GÉNERO. IV. EL CONVENIO DE ESTAMBUL COMO ARGUMENTO NORMATIVO. V. LA DESPROTECCIÓN, LA REVICTIMIZACIÓN Y LA CIFRA NEGRA DE CRIMINALIDAD COMO ARGUMENTOS EMPÍRICOS: 1. Planteamiento. 2. La cifra negra de criminalidad. 3. La desprotección y la revictimización. VI. LA DEFINICIÓN LEGAL DE CONSENTIMIENTO. VII. LA EQUIPARACIÓN DE MEDIOS COMISIVOS: 1. El planteamiento. 2. La victimización secundaria. 3. La razón analógica. 4. Lesión de los principios de lesividad y proporcionalidad. 5. El aprovechamiento de persona con voluntad anulada. 6. La supuesta eliminación del prevalimiento. VIII. UN HITO MÁS EN LA SENDA DE ENDURECIMIENTO DEL SISTEMA. IX. CONCLUSIONES. BIBLIOGRAFIA.

\section{LA FASCINACIÓN POR LA REFORMA PENAL'}

En las dos últimas décadas se han multiplicado las reformas del Código Penal (en lo sucesivo, CP). Tal y como ha concluido en un pormenorizado estudio Díez Ripollés (2013) los cambios legislativos se han caracterizado por dos notas. En primer lugar, por el creciente endurecimiento del modelo, perceptible en rasgos tales como el incremento de los límites máximos y mínimos de los marcos penales, la inexistencia de penas alternativas a la prisión, el aumento de las conductas susceptibles de persecución, la deficiente técnica legislativa, que hace posibles interpretaciones jurisprudenciales que vulneran la prohibición de la doble incriminación, o la mayor severidad de las condiciones de ejecución. En segundo lugar, por la inexistencia de diferencias entre derecha e izquierda políticas en la apuesta por el derecho penal. Para la derecha, como instrumento de orden, y para la izquierda, como motor de

1 En lo sucesivo utilizaré el género gramatical masculino para referirme a mujeres y a hombres, como aplicación de la ley lingüística de la economía expresiva. Cuando la oposición de sexos sea un factor relevante en el contexto explicitaré ambos géneros. 
cambio o transformación social. En ambos casos, con idéntico resultado: la agravación de la respuesta penal.

Normalmente, las reformas se fundamentan en razones que no disponen de aval científico, casos episódicos que cobran relevancia en los medios, y en la instrumentalización de lo que, en apariencia, exigen los compromisos internacionales, y persiguen, principalmente, un efecto comunicativo simbólico. No suelen existir evaluaciones previas o posteriores a la aprobación de las normas. Respecto de las evaluaciones previas, cuando las hay, es habitual la presencia de deficiencias de medios y de importantes fallas metodológicas. En cuanto a las evaluaciones posteriores, no se presupuestan partidas para medir qué impacto han podido tener las normas aprobadas sobre la realidad social, de modo que una misma figura delictiva puede reformarse varias veces en un tiempo reducido sin que el legislador llegue a conocer cuáles han sido los efectos reales de los distintos redactados (Díez Ripollés, 2003: 62-65).

Ello explica que la mayor parte de las reformas penales se instrumenten sobre la base de análisis rudimentarios y muy superficiales de la realidad que se pretende transformar, situación de la que da cuenta el dato de que en apenas 26 años se hayan producido del orden de 35 modificaciones legislativas. Más en concreto, y por lo que afecta a los delitos sexuales, se han producido cuatro profundas reformas en los años 1999, 2003, 2010 y 2015, lo que se ha traducido en un régimen jurídico particularmente duro (v.gr. y entre muchos otros ejemplos disponibles, el marco penal para los tipos agravados del delito de violación supera el del delito de homicidio doloso), y de connotaciones moralizantes (v.gr. la fijación de la edad sexual en 16 años).

Parece, así, que lo relevante no es tanto incidir sobre la realidad como sobre la opinión pública, mediáticamente condicionada (Soto Navarro, 2005, 2006). La justificación del legislador de la introducción de la prisión permanente en la exposición de motivos del Anteproyecto de la LO 1/2015 es paradigmática: hay que dar respuesta a la "percepción» de inseguridad de la población, para lo que resulta preciso un sistema legal que garantice «resoluciones judiciales previsibles que, además, sean percibidas en la sociedad como justas». Lo determinante no serán tanto los hechos como las percepciones sociales que de ellos se tengan.

En coherencia con este paradigma, la exposición de motivos del Anteproyecto de Ley Orgánica de Garantía Integral de la Libertad Sexual (en lo sucesivo, AP) justificó la necesidad de la reforma penal en «la percepción de insatisfacción social por la respuesta que la jurisdicción penal viene dando en los procedimientos que se siguen por delitos contra la libertad e indemnidad sexuales». El Proyecto de Ley Orgánica (en lo sucesivo, PLO) ha optado finalmente por suprimir la referencia. Del mismo modo, ha suprimido la referencia del AP al hecho de que mediante la reforma se pretende «reorientar el régimen 
de valoración de la prueba». Sin embargo, pese a tales supresiones, el núcleo de la reforma penal proyectada sigue intacto, lo que sugiere que se ha procurado no explicitar las verdaderas razones que motivan el cambio. En su lugar, ahora se alude en exclusiva, a las necesidades de ajuste al Convenio de Estambul, lo que, como veremos, es un simple pretexto, ya que el régimen jurídico vigente en el CP ya se adecúa al Convenio.

\section{EL PROYECTO DE LEY ORGÁNICA DE GARANTÍA INTEGRAL DE LA LIBERTAD SEXUAL²}

\section{LENGUAJES Y TRADUCCIONES}

Tal y como ha sucedido en otros casos, la tramitación de la reforma ha ido de la mano de un proceso judicial que pronto adquirió dimensión mediática. Concretamente, el caso conocido como "La manada de Pamplona»" lo que ha condicionado decisivamente el debate público dificultando una aproximación basada en parámetros científico-racionales a la cuestión (Ramírez Ortiz, 2018: 12-16). La dependencia del suceso mediático complica el debate porque en él se mezclan lenguajes distintos: el mediático, el del activismo social, el político y el jurídico. Sin duda, todos son necesarios y valiosos, pero cada uno denota una realidad distinta y tiene unos objetivos diferenciados, lo que conviene tener presente, pues es frecuente que se produzcan malos entendidos cuando los distintos interlocutores emplean distintos registros. No debemos minusvalorar, por ello, el papel que desempeñan los medios de comunicación, pues pueden inducir cambios de perspectiva en la opinión pública que acaben situando determinadas cuestiones en la agenda política dando lugar a modificaciones legales necesarias, pero debemos estar alerta ante el riesgo de que la norma jurídica resultante sea una mala traducción de una pretensión que se expresa en otro idioma.

Tres eslóganes, necesarios desde el punto de vista de la pedagogía social, han marcado la discusión pública: «No es abuso, es violación», «Yo sí te creo»y «Sólo el sí es sí». Lo que nos corresponde examinar es si su traducción técnica se ha producido en la dirección correcta, y, por tanto, si el recurso a la reforma penal nos conduce a una sociedad mejor y más igualitaria, como defienden los promotores de la reforma o, por el contrario, no sólo no logra tal objetivo sino

2 Publicado en el Boletin Oficial de las Cortes Generales el día 26 de julio de 2021.

3 La mejor prueba es el título de la publicación de la obra colectiva de Faraldo Cabana y Acale Sánchez (2018). 
que contribuye a la expansión del sistema penal, como prestigiosas asociaciones de juristas progresistas han mantenido (Grupo de Estudios de Política Criminal, 2021; Comisión Penal de Juezas y Jueces para la Democracia, 2021).

\section{LA EXPOSICIÓN DE MOTIVOS DEL PROYECTO}

El PLO tiene como precedentes la «Proposición de Ley de protección integral de la libertad sexual y para la erradicación de las violencias sexuales» presentada por el grupo parlamentario Unidas Podemos y el «Anteproyecto de Ley Orgánica de modificación del Código Penal para la protección de la libertad sexual de las ciudadanas y los ciudadanos», elaborado por la Comisión General de Codificación a finales del año 2018, si bien responde en mayor medida a la filosofía del primer texto.

Según señala la exposición de motivos del PLO, las violencias sexuales constituyen un problema estructural, vinculado a una cultura sexual arraigada en patrones discriminatorios, que repercute colectivamente sobre las mujeres, a quienes se transmite un mensaje de inseguridad y dominación y de reafirmación de un orden patriarcal. La mejor prueba de ello es que son mayoritariamente las mujeres quienes sufren estos delitos.

La ley proyectada pretende dar una respuesta global a ese problema mediante la instauración y puesta en marcha de una serie de medidas interdisciplinares de actuación institucional y profesional especializada y coordinada con la finalidad de abordar de modo multidimensional el fenómeno.

Además, el PLO propone relevantes reformas en el tratamiento jurídico de esas figuras delictivas. Tales reformas, según se explica, se inscribirían en la línea de las exigencias de la Convención sobre la Eliminación de Todas las Formas de Discriminación contra la Mujer (CEDAW), aprobada el día 18 de diciembre de 1979 por la Asamblea General de las Naciones Unidas, y de las Recomendaciones de su Comité de Expertos. Y, en particular, responderían a los requerimientos del Convenio del Consejo de Europa sobre Prevención y Lucha contra la Violencia contra la Mujer y la Violencia Doméstica, hecho en Estambul el 11 de mayo de 2011, al existir desajustes entre la regulación vigente y los principios contenidos en tal instrumento internacional. En suma, la regulación propuesta pretende reestructurar los delitos sexuales desde la perspectiva de género, de la que carecería el CP.

\section{LAS LEYES INTEGRALES}

No es frecuente encontrar hoy día normas jurídicas que desvaloricen a las mujeres, normas que establezcan diferencias de trato desigualitarias que privilegien el estatuto de los hombres. No obstante, como ha demostrado 
el feminismo de la diferencia, un derecho pretendidamente neutral puede resultar discriminador en su aplicación, al no tomar en cuenta la diferencia, pues el redactor de la ley suele dejar fuera de su ecuación la situación de desigualdad de base propia de las sociedades patriarcales, caracterizadas por la dominación masculina. Con ello se produce un resultado paradójico: la aplicación de la norma neutra perpetúa la realidad asimétrica (Larrauri, 2008: 28). La solución pasaría, entonces, por promover otra clase de derecho que tenga en cuenta la diferencia para luchar contra la desigualdad subyacente.

Hombres y mujeres somos titulares en igual medida del derecho a la libertad sexual, derecho vinculado con la intimidad personal (art. 18.1 CE), la dignidad humana y el libre desarrollo de la personalidad (art. 10.1 CE). Sin embargo, la realidad evidencia que en este ámbito las víctimas de las violaciones del derecho son mayoritariamente mujeres, situación que debe merecer la atención de los poderes públicos, que han de promover la protección de tal libertad para proscribir la discriminación. Ello puede tener lugar en dos planos: creando derechos y obligaciones positivas de prestación, y tipificando determinadas conductas lesivas del libre ejercicio de la sexualidad.

El PLO pretende actuar en ambos planos emulando el modelo de la Ley Orgánica 1/2004 de 28 de diciembre, de Medidas de Protección Integral contra la Violencia de Género. Por lo que respecta al primer plano, la propuesta normativa incluye medidas de prevención, sensibilización, formación, especialización y mejora de la asistencia a quienes padecen violencias sexuales otorgando un tratamiento similar, en algunos aspectos, al que se da a las víctimas de la violencia intrafamiliar. Dejando a un lado ciertos extremos que podrían ser objeto de puntual mejora, ${ }^{4}$ la propuesta legislativa en este plano cobra pleno sentido a los efectos pretendidos, pues la forma más eficaz de combatir el fenómeno es actuando contra sus causas estructurales, ámbito en el que es perfectamente legítimo introducir normas que dispensen tratamientos diferenciados para garantizar la igualdad.

No es objeto de este trabajo el análisis de los aspectos no penales. En cualquier caso, es elocuente el escaso eco que han tenido, lo que patentiza el

4 Debido a la equiparación de realidades cualitativamente distintas. Por un lado, el concepto legal de violencia sexual abarca conductas muy heterogéneas en intensidad y gravedad. Por otro, el fenómeno de la violencia sexual tal y como es concebido en el PLO presenta diferencias con la violencia que reguló la LO 1/2004). Véase, como ejemplo de la disfunción, el art. 41 del PLO, que otorga a toda víctima de violencias sexuales, con independencia de su relación con el agresor u otras circunstancias, prioridad en el acceso al parque público de viviendas. 
papel egocéntrico que desempeña el derecho penal en todo debate público, no admitiendo rivales que puedan restarle protagonismo.

Buen ejemplo de ello es la generalización de la técnica legislativa de la ley integral, que combina aspectos penales y extrapenales, y que, por lo que nos ocupa, plantea grandes riesgos, pues puede transmitir la idea de que el modelo de igualdad debe configurarse necesariamente a partir de un núcleo duro penal sobre el que se edifica el aparato preventivo y asistencial, y sin el que este aparato no sería posible. Una opción de política legislativa que, al vincular ambos planos, parece convertir la reforma penal en conditio sine qua non de las políticas sociales y preventivas, aun cuando tal reforma pudiera no ser necesaria o no serlo en la extensión o dirección propuestos (véase Laurenzo Copello, 2007, sobre la «vis atractiva» del derecho penal a propósito de la LO 1/2004). Por otra parte, al poner el acento en la reforma penal, tal y como el debate público sobre esta cuestión ha patentizado, esta opción legislativa enmascara el hecho de que el derecho penal tiene un sesgo de clase que acaba reproduciendo las desigualdades estructurales subyacentes (Larrauri, 2007). Pero, además, este modelo tienta al legislador a continuar la senda y a fijarse como objetivos regulativos distintos colectivos de víctimas potenciando la conformación de un derecho identitario (Díez Ripollés, 2019: 28-29) por el simple hecho de haber padecido hechos delictivos ${ }^{5}$.

\section{LAS PRINCIPALES PROPUESTAS PENALES}

La exposición de motivos del PLO es muy parca respecto de las concretas razones técnicas que fundamentan la necesidad de la reforma penal. Las propuestas centrales que materializarían el cambio de paradigma son las siguientes:

a. La eliminación de la distinción entre agresión y abuso sexual y la equiparación penológica de los atentados sexuales. Según el PLO, de esta forma pasan a considerarse agresiones sexuales «todas aquellas conductas que atenten contra la libertad sexual sin el consentimiento de la otra persona, cumpliendo así España con las obligaciones asumidas desde que ratificó en 2014 el Convenio de Estambul». Así, incluye en un mismo tipo penal conductas que hoy se sancionan de manera distinta (como agresión, si

5 Como ejemplos, la reciente aprobación de la Ley Orgánica 8/2021, de 4 de junio, de Protección Integral a la Infancia y la Adolescencia frente a la Violencia, y el debate sobre la conveniencia de la aprobación de la Ley Integral de Protección de las Víctimas de Trata de Personas. 
concurre violencia o intimidación, o como abuso, en los demás supuestos en los que el consentimiento prestado se considera viciado o inválido o en los que no existe). A su vez, dentro de las agresiones diferencia en función de la existencia o no de acceso por vía vaginal, anal o bucal, y a partir de dichos tipos básicos contempla modalidades agravadas. Entre ellas, y afirmando encontrarse en línea con las previsiones del Convenio de Estambul, se introduce la circunstancia cualificatoria agravante específica de género en estos delitos

b. La supresión del prevalimiento.

c. La introducción expresa, como forma de comisión de la agresión sexual, de la denominada «sumisión química» o mediante el uso de sustancias y psicofármacos que anulan la voluntad de la víctima.

d. Llamativamente, porque la exposición de motivos no dedica mención alguna a la cuestión, la introducción de una definición expresa de lo que debe entenderse por consentimiento. En la redacción propuesta para el art. 178.1 CP, se define así: «Sólo se entenderá que hay consentimiento cuando se haya manifestado libremente mediante actos que, en atención a las circunstancias del caso, expresen de manera clara la voluntad de la persona».

\section{LA PERSPECTIVA DE GÉNERO}

Una de las principales críticas que se dirigen a la normativa vigente y a quienes cuestionan la necesidad de la reforma penal es la ausencia de perspectiva de género. Por eso creo conveniente hacer algunas aclaraciones (más extensamente, Ramírez Ortiz, 2019):

a. El análisis del derecho y sus instituciones con las herramientas antidiscriminatorias que proporciona el movimiento feminista no constituye una opción, sino una obligación internacional en virtud, entre otras normas, del CEDAW, el Convenio de Estambul y la Recomendación CM/Rec (2019) del Comité de Ministros a los Estados miembros para prevenir y combatir el sexismo. También constituye una obligación interna, pues la Constitución impone la garantía del valor jurídico igualdad (art. 14 CE), instando a los poderes públicos a que promuevan las condiciones que aseguren que el hecho de la diferencia no sea fuente de discriminación (art. 9.2 CE). Del mismo, tal aproximación nos permite reflexionar colectivamente sobre cómo se legisla y sobre cómo se aplican las normas, con la finalidad de promover un derecho legal y judicial más igualitario. 
b. Tales herramientas integran lo que se conoce como "perspectiva de género». Si la desigualdad no sólo se nutre de condiciones materiales que generan asimetría, sino también de representaciones mentales, de prejuicios culturales generados por siglos de historia de dominación masculina, que pueden aflorar, aun de forma inadvertida, en los razonamientos y conductas de los justiciables y de los operadores jurídicos, la perspectiva de género nos permite identificar aquellas instituciones, reglas y prácticas del derecho que crean, legitiman y perpetúan la discriminación, así como señalar el camino para derogarlas, transformarlas y/o sustituirlas por otras.

c. Ahora bien, así como no existe un único feminismo ${ }^{6}$ tampoco existe, estrictamente, un único modo de aproximarse, con el instrumental de la perspectiva de género, a los problemas jurídicos, pues aun cuando se empleen, al menos metodológicamente, las mismas herramientas analíticas, los análisis suelen realizarse desde concepciones políticas y culturales más amplios, que pueden divergir hasta ser opuestos. No son, en consecuencia, irrelevantes las premisas ideológicas, los puntos de partida desde los que se arranca. Y la concepción que tengamos del sistema penal, de los rendimientos que del mismo cabe obtener, y las limitaciones y los riesgos que supone recurrir a él, forman parte de ese sustrato ideológico desde el que evaluar las estrategias empleadas para combatir el enemigo común de la desigualdad. Esta aproximación nos permite identificar discursos o propuestas que, realizados con el instrumental de la perspectiva de género, pueden no acabar vertiendo, aun involuntariamente, hacia la emancipación sino hacia el control.

d. Por otra parte, ningún debate político o social se produce en el vacío. Y el debate político y mediático sobre la necesidad de la reforma penal, al que se ha vinculado el debate sobre el proceso de emancipación de la mujer, se produce en un momento caracterizado por la desaparición del Estado del bienestar y la refundación del pacto social en una fuente distinta de legitimación, la ley penal: como los Estados no pueden erradicar las causas profundas de la desigualdad y la discriminación, tienden a redefinir todo conflicto social en clave penal cambiando el foco: de la inseguridad individual fruto del mercado a la inseguridad personal vinculada con el delito.

En mi opinión, conviene evaluar cualquier propuesta de modificación de la ley penal que afecte a la libertad sexual teniendo presentes tales puntos

6 La literatura sobre la cuestión es abundante. Véase, entre otros, el análisis de Vivas Larruy (2016: 43-48). 
de partida, sin obviar ninguno de ellos, pues podría ocurrir que, pretendiendo impulsar el proceso de emancipación de la mujer contribuyamos, aun involuntariamente, a degradar el sistema de garantías penales, procesales y sustantivas, sin obtener el resultado pretendido; como también podría ocurrir, que, inducidos por un falso entendimiento de las garantías, obstaculicemos dicho proceso. Como señala con acierto Arduino (2019: 265-266), se trata de «romper el cerco de impunidad que el sistema penal construyó tras siglos de invisibilización de las cuestiones de género sin caer en el punitivismo demagógico».

Por tanto, para cuestionar una determinada regulación no basta con afirmar que se ha elaborado sin perspectiva de género. Han de identificarse las razones por las que carece de tal perspectiva, y explicarse los motivos por los que la regulación proyectada pondría fin a la situación discriminatoria que la que pretende derogar contribuye a mantener.

\section{EL CONVENIO DE ESTAMBUL COMO ARGUMENTO NORMATIVO}

Tanto en el debate público como en la exposición de motivos del PLO se ha venido afirmando que la reforma penal es una exigencia impuesta por el Convenio de Estambul, cuyo art. 6 establece la obligación de las Administraciones públicas de actuar desde el enfoque de género en todas sus actuaciones, incluidas las legislativas. Tal afirmación, que parece haberse convertido en axiomática, no es verdadera.

Un buen enfoque metodológico exige clarificar qué concreta obligación o compromiso omitido es el que debe ser preceptivamente incorporado al derecho interno para adecuarse al Convenio. Para ello, ha de compararse la norma convencional e identificar la laguna en la regulación nacional, pues puede ocurrir que la pretendida obligación normativa sea, en realidad, un determinado punto de vista acerca de lo que nuestro ordenamiento debería decir o también que no exista la laguna que pretende colmarse.

El art. 36.2 del Convenio de Estambul exige la necesidad de que el consentimiento sexual, de existir, se haya prestado de manera voluntaria «como manifestación del libre arbitrio de la persona considerado en el contexto de las condiciones circundantes». Sobre la base de tal precepto se viene a sostener que ha de reformarse nuestra regulación en profundidad para que gire en torno al consentimiento y no se centre en el medio empleado para doblegar la voluntad de la víctima. Sin embargo, la regulación vigente ya gira en torno al consentimiento. Así, el art. 181.1 CP castiga al que «[...] sin violencia o intimidación y sin que medie consentimiento, realizare actos que atenten contra la libertad sexual de otra persona». 
Se apela igualmente al Convenio para introducir la circunstancia agravante específica de que la víctima del ataque sexual sea o haya sido esposa o pareja del agresor. Lo cierto es que en el catálogo de agravantes genéricas ya disponemos de la circunstancia de parentesco del art. 23 CP. Por otro lado, se alude al Convenio para fundamentar la necesidad de una agravante específica de género. Sin embargo, no sólo el Convenio no contiene tal exigencia (vid. art. 46), sino que nuestro $\mathrm{CP}$ considera el género como uno de los motivos discriminatorios que permiten aplicar la circunstancia agravante genérica del art. 22.4. ${ }^{\mathrm{a}} \mathrm{CP}$.

Finalmente, el Convenio no exige en precepto alguno diferenciar entre las diferentes modalidades de atentado contra la libertad sexual, por lo que tampoco impone la equiparación de las consecuencias jurídicas vinculadas a los supuestos de hecho que actualmente integran los delitos de agresiones y los abusos sexuales.

Recordemos que la reforma de los delitos sexuales en la LO 1/2015 se justificó en la necesidad de trasponer la Directiva 2011/93/UE. Sin embargo, como ya sucedió con la reforma de 2011, en ese caso en relación con la Decisión Marco 2004/68/JAI, la Directiva no exigía realmente la incorporación de los contenidos que acabaron incluyéndose en el Código, que se endureció notablemente. La decisión legislativa fue una opción política, no una exigencia internacional.

Una norma, un enunciado de un discurso prescriptivo, no es verdadera ni falsa. Una proposición normativa, o enunciado que recae sobre una norma, afirmando su existencia, validez o efectividad, sí puede ser verdadera o falsa. A la vista de lo expuesto, es posible concluir que la proposición normativa «la regulación de los delitos sexuales no se ajusta al Convenio de Estambul» no es verdadera.

\section{LA DESPROTECCIÓN, LA REVICTIMIZACIÓN Y LA CIFRA NEGRA DE CRIMINALIDAD COMO ARGUMENTOS EMPÍRICOS}

\section{PLANTEAMIENTO}

De la mano del argumento normativo examinado se sostiene que la regulación vigente incurre en un triple defecto: desprotege a las mujeres y las revictimiza, lo que explicaría una cifra negra de criminalidad que no aflora en las estadísticas.

\section{LA CIFRA NEGRA DE CRIMINALIDAD}

Es indudable que en este ámbito existe una cifra negra de criminalidad. Y que no es fácil su determinación. Las encuestas de victimización pueden 
ser un buen instrumento, pero son insuficientes por sí solas. Por eso, en la investigación criminológica se recomienda la utilización de más de un método de investigación. Por otra parte, el valor de las inferencias estadísticas que puede obtenerse de las encuestas dependerá de diversas variables, tales como el tamaño y composición de la muestra, el tipo de preguntas que se realizan, la forma (presencial, telefónica, por correo, etc.) mediante la que se instrumentan las preguntas o los estudios de validación empleados.

En las encuestas de victimización suele definirse la categoría criminológica o sociológica "violencia sexual» con gran amplitud, agrupando conductas muy heterogéneas. Por tanto, es aconsejable, en primer lugar, identificar los datos relevantes. En segundo lugar, interpretarlos correctamente para saber lo que nos dicen. Finalmente, decidir qué hacer con ellos. En suma, puede haber violencias sexuales no penalmente relevantes, como numerosas violencias simbólicas y violencias sexuales penalmente trascendentes de gravedad muy diversa. Una propuesta de reforma que pretende equiparar la respuesta penal a violencias sexuales heterogéneas ha de ser capaz de explicar el fundamento criminológico que justifica la equiparación.

Por otra parte, debe evaluarse si la cifra negra de criminalidad guarda relación con la tipificación delictiva o con las prácticas investigativas o de enjuiciamiento, pues en múltiples ocasiones se acude al CP para buscar respuesta a problemas cuyas soluciones se encuentran en otros sitios. Sin embargo, no hubo estudios empíricos de base en el origen del PLO, sino la conjunción de diversos casos mediáticos junto a algunas resoluciones judiciales controvertidas (ni siquiera un estudio basado en la estadística judicial), resoluciones controvertidas no tanto por sus efectos (eran sentencias de condena muy severas) como por haber acudido a la figura del abuso por prevalimiento de una situación de superioridad en lugar de a la agresión por intimidación. Por tanto, admitiendo la existencia de la cifra negra de criminalidad, faltan datos empíricos que permitan conectar el fenómeno con los supuestos déficits de tipificación en el CP.

\section{LA DESPROTECCIÓN Y LA REVICTIMIZACIÓN}

Si la regulación vigente desprotege o revictimiza y si la propuesta da solución a esos problemas es algo que iremos viendo el analizar los ejes de la reforma proyectada. Conviene, no obstante, recordar aquí algunas cosas:

a. Es preciso tener presente la existencia de dos momentos nítidamente diferenciados: el de creación de la norma o legislativo, y el de su aplicación o judicial, o en otros términos, el momento de la criminalización primaria o definición del delito, y el de la criminalización secundaria o definición del delincuente. Es importante retener la distinción, pues 
pudiera ocurrir que el efecto de desprotección o revictimización se deba a déficits en el momento judicial y no en el legislativo.

b. Por lo que respecta al momento judicial, no hay que olvidar que el proceso penal se configura como procedimiento de protección jurídica de los individuos, por lo que tiene una doble finalidad: el castigo del culpable y la tutela del inocente. Esta dualidad de fines explica que aquél cumple también su finalidad cuando concluye por sentencia absolutoria.

c. En los sistemas constitucionales el proceso judicial se instaura para verificar si la hipótesis formulada por la acusación, que atribuye a un individuo determinado un hecho particular, encuentra respaldo en la prueba practicada más allá de toda duda razonable, en un contexto contradictorio que permita cuestionar e incluso refutar tal hipótesis, cuestionamiento que, en consecuencia, alcanza a las informaciones provenientes de los propios medios de prueba en que se sustenta la hipótesis, como los relatos de los testigos. No se trata, por ello, de que el juez «crea» o «no crea» al testigo víctima. Como ha señalado con acierto San Miguel Bergareche (2018) se trata de "probar» no de "creer», lo que tiene lugar mediante la evaluación crítica del conjunto de elementos de juicio que conforman el cuadro probatorio.

d. No es función del juez penal hacer política social ni política criminal. El juez penal no puede combatir la desigualdad de género, ni la discriminación, porque no es su función institucional. No lucha contra la violencia de los hombres sobre las mujeres. Otros poderes públicos, sí lo hacen. Las instancias encargadas de la persecución y acusación (policía y fiscalía), también. Cuestión distinta es que el efecto reflejo de una decisión de condena sea el de dar respuesta al conflicto social, en los estrictos términos en los que el derecho penal lo haya redefinido, pero ello es ajeno a la función jurisdiccional y no debe pesar en la conciencia del juez penal cuando juzga y sentencia. Del mismo modo, ello no obsta para que el juez penal deba ser consciente de la realidad social cuyos hechos ha de enjuiciar y del contexto en que tales hechos se enmarcan, tanto para valorar la prueba que se le ofrezca como para aplicar la ley penal.

Teniendo presentes los argumentos normativos y empíricos alegados en favor de la reforma, examinaremos las distintas propuestas articuladas en el texto.

\section{LA DEFINICIÓN LEGAL DE CONSENTIMIENTO}

Según quienes promueven el cambio, la regulación vigente desprotege

y revictimiza al no basarse en el consentimiento, pues exige una negativa 
explícita a la mujer que no quiere mantener una relación sexual ya que, en otro caso, se presume que presta el consentimiento, lo que da lugar a que la mayoría de los órganos judiciales cuando no existe tal negativa explícita entiendan que hay consentimiento. La inclusión de una definición legal del consentimiento implicaría un cambio de paradigma que evitaría este efecto. Como seńalan Faraldo y Acale (2018: 25) «El objetivo es pasar del «No es no» al «solo sí y la persistencia del sí es consentir», como «la única forma de proteger a las mujeres que... reaccionan ante un suceso bloqueándose», pues «[...] la regulación actual [...] protege menos a las víctimas [...] que no han sido capaces de oponer una resistencia activa o huir».

Lo cierto es que la regulación vigente ya se basa en el consentimiento. El $\mathrm{CP}$ no exige que la víctima haya emitido una negativa u ofrecido resistencia al agresor para considerar delictivo un atentado contra la libertad sexual. Así, el art. 181.1 CP sanciona como atentado contra la libertad sexual a quien «sin que medie consentimiento, realizare actos que atenten contra la libertad o indemnidad sexual de otra persona».

El CP, como dice su exposición de motivos, es una constitución en negativo. Como texto iusfundamental, quien pretende modificarlo sobre la base de razones empíricas tiene la carga argumentativa estadística. Bajo mi punto de vista, la afirmación de que la mayoría de los tribunales, cuando no existe una negativa explícita, entienden que hay consentimiento, carece de base. Pese a la facilidad de su consulta, no existe ningún estudio de la estadística judicial oficial que identifique en cuántos casos se dictó erróneamente sentencia absolutoria por estimar que existía consentimiento pese a que la víctima no lo manifestó, expresa o tácitamente. Por el contrario:

a. En determinados atentados contra la libertad sexual (v.gr. tocamientos sorpresivos), es inherente a la dinámica comisiva que no haya que esperar a que la víctima manifieste su negativa para entender satisfechas las exigencias del tipo.

b. En los demás, es consustancial a la función judicial, atender a todas las circunstancias concurrentes. Agustín Malón (2020: 71-77) ha destacado que en el consentimiento sexual hay que distinguir varios planos. Por un lado, el asentimiento interno al acto sexual; en segundo lugar, un comportamiento o manifestación externa de ese asentimiento; en tercer lugar, la interpretación del estado interno de la mujer por parte del hombre a partir de la conducta externa y, finalmente, la valoración del estado interno del hombre por parte de un observador externo, como podría ser la persona que juzga el caso. El asentimiento interno puede tener motivaciones muy diversas (v.gr. un deseo sexual genuino, un impulso hedonista o romántico, compasión hacia la pareja a la que se va a dejar, 
venganza a la pareja que nos traicionó, etc., pudiendo coexistir intereses, necesidades y deseos ambivalentes). El comportamiento externo, por su parte, está sometido a numerosos elementos contextuales y, en algunos casos, puede reflejar las contradicciones internas. Del mismo modo, el hombre puede interpretar los signos externos influenciado por creencias, prejuicios o convenciones sociales que pueden llevarle a interpretar de determinada manera tales signos. Por último, quien juzga ha de interpretar las conductas externas de ambos.

Pues bien, actualmente está generalizada en la judicatura la opinión de que para valorar si la participación en el acto sexual es voluntaria hay que atender a las palabras, hechos o cualquier otro indicador denotativo del consentimiento, lo que conduce probatoriamente a la necesidad de examinar el asentimiento interno de la mujer y el modo en que se manifestó, así como el estado interno del hombre y los actos que llevó a cabo. No es correcto afirmar que, judicialmente, la pasividad equivale a consentimiento. El silencio o la ausencia de resistencia, por sí solos, no implican consentimiento, aunque pueda haber casos en los que, atendidas otros datos indicadores, pueda concluirse que existió un consentimiento tácito. Se trata de una cuestión que habrá de apreciarse caso por caso, y los eventuales errores que puedan producirse en la valoración probatoria en sentencias concretas son susceptibles de ser corregidos a través del sistema de recursos. No hay, en suma, residuo androcéntrico alguno en este aspecto en el CP, ni efecto de desprotección para las mujeres.

Quienes defienden la reforma señalan, no obstante, que es necesario dar un paso más, e introducir el modelo del «consentimiento afirmativo», de modo que la pasividad y el silencio nunca pudieran ser interpretados como manifestación de voluntad: se partiría así de la presunción de que no existe consentimiento hasta que haya autorización expresa que indique lo contrario. En cuanto a la fórmula verbal, en el AP se optó inicialmente por una definición legal relativamente cerrada, bajo la premisa de que cuanto más exigente fuera la fórmula, más protegidas estarían las mujeres y más se castigaría a los agresores. Así, se señalaba: «Se entenderá que no existe consentimiento cuando la víctima no haya manifestado libremente por actos exteriores, concluyentes e inequívocos conforme a las circunstancias concurrentes, su voluntad expresa de participar en el acto.»

Como es de ver, esta propuesta, con la finalidad de erradicar toda experiencia sexual no efectivamente consentida, definió qué gestos externos de la mujer debían ser considerados por el hombre y por quien juzga como un consentimiento válido. Sin embargo, pronto se advirtió que podía generar: 
a. Un efecto de sobreinclusión: si se exige que el consentimiento sexual revista una concreta forma se produce el riesgo de que se entiendan prohibidas conductas en las que hubo un asentimiento interno real, aunque no se ajustara a la fórmula legal, como sucede en los supuestos de consentimiento tácito, pero cierto, o expresado a través de actos equívocos, existiendo asentimiento interno.

b. Un riesgo de revictimización ańadido: para determinar si todos los elementos de la fórmula están presentes, el interrogatorio habrá de centrarse en si hubo o no tales «actos exteriores, concluyentes e inequívocos» y si el acusado podía creer razonablemente que la otra parte mostraba con ellos «su voluntad expresa de participar en el acto». En consecuencia, habrá que realizar una indagación detallada sobre el tipo de interacción y la conducta de la víctima previa y coetánea al acto sexual o sobre el modo en que la víctima suele prestar el consentimiento sexual ${ }^{7}$. Por otra parte, podría haber casos en los que la mujer hubiera expresado la voluntad mediante actos exteriores, concluyentes e inequívocos, pese a disentir internamente de la relación sexual por sentirse intimidada, lo que podría incrementar las posibilidades de invocar el error de tipo respecto del elemento del consentimiento. En cualquier caso, ello frustraría la pretensión de que deje de someterse a un intenso escrutinio la conducta de la víctima para centrarse en exclusiva en el análisis del comportamiento del acusado.

c. La posible lesión del art. $24.2 \mathrm{CE}$ tal y como implícitamente reconoce la exposición de motivos del AP al señalar que se busca cambiar la perspectiva sobre el régimen de la valoración de la prueba. Tal cambio de perspectiva podría comprometer el derecho a la presunción de inocencia, que proscribe toda inversión de la carga de la prueba sobre los elementos constitutivos de la infracción penal. La norma puede ser interpretada en el sentido de entender que, comoquiera que la acusación no puede acreditar la presencia de un hecho negativo, debe ser la defensa quien acredite que la víctima prestó el consentimiento en los términos explicitados por la formulación legal. Bajo esta interpretación, sólo mediante la justificación defensiva de que concurrieron las circunstancias exigidas por la norma (actos exteriores,

7 V.gr. para demostrar que la víctima manifestó «libremente por actos exteriores, concluyentes e inequívocos su voluntad expresa de participar en el acto», la defensa podría hacer preguntas tales como "iNo es verdad que usted misma se quitó la ropa interior cuando el acusado se lo pidió?»; «¿no es verdad que usted le pidió que usase un preservativo?», que no podrían declararse impertinentes. 
concluyentes e inequívocos y voluntad expresa de participar en el acto) cabría reputar el hecho penalmente irrelevante o atípico.

En otros términos: someter la validez del consentimiento a una determinada forma puede dar lugar a interpretaciones de los tribunales similares a las que hacen de las causas de justificación procedimentales, tal y como sucede en los supuestos de interrupción voluntaria del embarazo o en los casos de consentimiento en los transplantes de órganos y cirugía transexual; esto es, pueden interpretar que es carga defensiva acreditar y probar la concurrencia de todos los elementos que incorpora la fórmula legal del consentimiento. Tal interpretación, bajo mi punto de vista, sería errónea, pues consideraría que, en principio, mantener relaciones sexuales es una acción típica que puede no ser antijurídica cuando concurra la causa de justificación, pero no sería descartable que fuera asumida jurisprudencialmente.

Para intentar salvar algunas de esas objeciones, la redacción final del PLO ha optado por otra fórmula menos exigente: «Sólo se entenderá que hay consentimiento cuando se haya manifestado libremente mediante actos que, en atención a las circunstancias del caso, expresen de manera clara la voluntad de la persona». Sin embargo, la fórmula sigue ofreciendo problemas:

a. El efecto de sobreinclusión, aun mitigado, persiste. El prelegislador presupone que en toda relación sexual hay una parte que ofrece algo y otra que acepta el ofrecimiento, lo que no se corresponde con la complejidad y diversidad de las relaciones sexuales. En este sentido, la exigencia de «actos» que «expresen» la voluntad de la persona de manera "clara» puede dar lugar a que haya tribunales que interpreten que el consentimiento tácito queda prohibido, pues, según el DRAE «tácito» es lo que no se expresa o no se dice, pero se supone o sobreentiende, lo que pugnaría con el recurso al verbo "expresar» empleado en la formulación legal. Por otra parte, la exigencia de «claridad» puede convertir en punibles supuestos en los que podemos convenir en que no se produce lesión alguna del bien jurídico. Pensemos en escarceos eróticos en los que quienes participan no verbalizan su voluntad, aceptan tácitamente explorar hasta dónde puede llegar la otra persona, no expresan oposición a lo que viven, ignorando en ese momento a dónde llevará la situación. En un momento dado, uno de los participantes lleva a cabo una acción sexual que supone una progresión en la intensidad del contacto, instante en el que, quien había permanecido pasivo, a la expectativa, expresa explícitamente su negativa a continuar, y la otra persona atiende la petición. $O$ piénsese en una persona, que, por curiosidad, se ve envuelta en una práctica sexual que nunca ha realizado sin expresar su consentimiento 
y que, en un momento dado, decide interrumpir. Según la definición legal, nos encontraríamos ante relaciones sexuales no consentidas que deberían ser castigadas. Muy ilustrativos son los ejemplos, a los que me remito, que pueden verse en Camarena Grau (2021: 43-44).

b. El riesgo para la presunción de inocencia también permanece. Los tribunales pueden interpretar, al igual que con la fórmula más rígida, que es carga defensiva acreditar y probar la concurrencia de todos los elementos que incorpora la fórmula legal del consentimiento («actos que expresen de manera clara la voluntad») por las razones que ya examiné con anterioridad.

c. Respecto del riesgo de revictimización, la nueva formulación no lo elude, por las razones que expondré en VII.2.

No cabe descartar, como sostiene Agustín Malón (2020: 77-78), que lo que el legislador pretenda, en el fondo, no sea otra cosa que lanzar simplemente un mensaje simbólico confiando en que quienes juzgan no apliquen la norma tal y como está redactada. En definitiva, la norma no añadiría nada nuevo a lo que ya existe. Sin embargo, legítimamente, los tribunales pueden interpretar que hay una racionalidad, no sólo simbólica, en el cambio legal, y que si se ha producido es porque el legislador ha pretendido un cambio de orientación en la interpretación de la norma y evaluación de la prueba. Es evidente, en consecuencia, que el coste que supone su introducción, por los riesgos que encierra su aplicación estricta, es mayor al pretendido beneficio que podría obtenerse. En este punto, no está de más recordar, como luego veremos, que los principales problemas no son de orden sustantivo, sino probatorio, y queningunareformadela normasustantivasolventarálosproblemasqueplantean los supuestos de testimonio único no corroborado: frente a la afirmación de la víctima de que no consintió el acto sexual, puede oponerse la negación de la persona acusada, expresiva de que aquélla sí consintió dicho acto.

Por último, es preciso hacer patente una inconsistencia: el texto sigue manteniendo, inexplicablemente, una norma moralizante: la que fija la edad mínima para prestar el consentimiento sexual en los 16 años. La subsistencia de esta norma, a la que da cobertura la reforma, tiene, a mi entender, un enorme poder simbólico, pues, frente a la idea que subyace a quienes promueven el cambio legal (el derecho penal sexual ha gozado de una evolución lineal y coherente, basada en un progresivo reforzamiento de la protección de la libertad sexual desde 1995), cabe otra interpretación: todas las reformas sucesivas del Código se han ido distanciando de un derecho penal sexual estructurado en torno a la protección de la libertad sexual individual, y han abierto el camino a la resurrección de un derecho penal sexual con fuertes connotaciones moralizadoras (Díez Ripollés, 2019). 


\section{LA EQUIPARACIÓN DE LOS MEDIOS COMISIVOS}

\section{EL PLANTEAMIENTO}

El verdadero eje estructurador de la reforma es la equiparación de las distintas modalidades de ataque a la libertad sexual. Propuesta acompañada de la supresión del término «abuso», y de la eliminación del prevalimiento. En apoyo de la propuesta se sostiene que de esta forma se evita la victimización secundaria, pues pasaría a ocupar el centro del debate el acto realizado por el agresor si contar con el consentimiento de la víctima. En opinión de Acale (2019: 92), así se evita la revictimización «[...] en la medida en que si no se pudiera probar fácilmente la violencia o la intimidación, todavía sería posible probar de una forma menos traumática, la existencia de una situación de prevalimiento objetivo y/o subjetivo, evitando técnicas invasivas de la privacidad». Por otra parte, se alega que una técnica similar se sigue en los delitos de trata de personas (177 bis CP) y de explotación de la prostitución (187.1 CP).

\section{LA VICTIMIZACIÓN SECUNDARIA}

Veamos, en primer lugar, si la equiparación evitaría la victimización secundaria. Cuando el investigador recibe una denuncia, debe procurar obtener de su fuente primaria, la víctima, el mayor grado de información posible para elaborar una hipótesis y buscar otras fuentes de prueba alternativas, así como elementos de corroboración. Por tanto, no le es irrelevante cómo se desarrolló la interacción sexual en concreto: si el denunciado golpeó a la víctima para doblegar su voluntad, si la amenazó para atemorizarla, si ejecutó el hecho teniendo aquélla anulada la conciencia, etc, pues en función de ello orientará la búsqueda de las correspondientes fuentes informativas y elementos de corroboración.

Si se pasa a formular acusación, el acusador ha de identificar la hipótesis fáctica resultante de la investigación que somete a verificación en juicio. Por tanto, debe describir la conducta cuyo castigo pretende. La acusación no puede limitarse a hacer una descripción genérica pues, en otro caso, impediría el adecuado ejercicio del derecho de defensa (v.gr. posiblemente no sea idéntica la defensa que pueda desplegarse frente a una acusación en la que se afirme que la víctima estaba despierta que frente a otra que sostenga que estaba inconsciente). Descrita la hipótesis, la acusación ha de acreditarla a través de los medios de prueba que estime pertinentes, y el defensor puede refutarla.

Siendo ello así, es consustancial a su propia función que el investigador o el acusador formulen preguntas a la víctima, bien para elaborar la hipótesis, bien para acreditar la hipótesis una vez formulada, lo que no evitará un 
interrogatorio que afectará inevitablemente a la intimidad. Especialmente en un modelo de derecho penal sexual, como el nuestro, excesivamente genitalizado, en el que los aspectos anatómicos cobran especial relevancia por llevar asociadas notables diferencias penológicas.

Por otra parte, toda declaración que una persona que afirma ser víctima de un delito realiza en el proceso le supone, perse, un sufrimiento ańadido, pues se le exige que recuerde una experiencia que, de ser cierta, sería traumática. Además, la recuperación de la información que proporciona se realiza en un contexto inevitable y necesariamente contradictorio, en el que puede cuestionarse su relato. Un proceso penal informativo, construido para descubrir la verdad, garantizar derechos y minimizar el riesgo de abuso y error, lleva aparejado un grado de sufrimiento ineliminable. El propio Convenio de Estambul reconoce en el art. 54 que puede haber casos en los que las preguntas sobre los antecedentes sexuales y el comportamiento de la víctima sean necesarias. Ciertamente, hay parte de sufrimiento que puede ser innecesario y que debe ser corregido mediante prácticas probatorias adecuadas aplicando instrumentos de los que ya disponemos. Así, la Ley 4/2015, del Estatuto de la Víctima del Delito y el art. 709 de la Ley de Enjuiciamiento Criminal, entre otros ${ }^{8}$. Pero, atendido el contenido vigente del CP, ese sufrimiento adicional innecesario no tiene tanto que ver con las hipótesis normativas a probar o refutar como con la admisibilidad de preguntas irrelevantes (Rueda Soriano, 2021).

\section{LA RAZÓN ANALÓGICA}

Creo que la analogía es inaplicable por falta de identidad de razón entre los supuestos de hecho: tanto en los delitos de trata de personas como en los

8 Instrumentos de los que se hace eco la STS 383/2021 (ponente Javier Hernández García) «[...] el derecho a la intimidad de la persona que aparece como presunta víctima del hecho justiciable actúa como parámetro normativo de admisión de aquellos medios de prueba que puedan afectarlo de manera significativa- vid. arts. 22 y 25 c) Estatuto de la Víctima [...]. Ni el interés público en la investigación de un delito ni el derecho a la prueba de las partes del proceso penal, incluso de la persona acusada, justifican por sí y sin ninguna otra consideración ponderativa una intervención que recaiga sobre la esfera íntima de un tercero. Ninguna persona puede verse despojada a la ligera de sus derechos por la sola razón de que sea llamada al proceso ya sea como testigo o en cualquier otra condición». En este punto es preciso señalar que el PLO reforma nuevamente el art. 709 Lecrim añadiendo a la regla general de prohibición de "preguntas innecesarias relativas a la vida privada que no tengan relevancia para el hecho delictivo» el inciso «en particular, a la intimidad sexual», modificación innecesaria pues nada añade al objeto regulativo. 
de explotación de la prostitución, hay otros bienes jurídicos en juego que justifican la acumulación de conductas diversas. Pero, además, existen reglas concursales (177 bis. 9 y $187.3 \mathrm{CP}$ ) que remiten a las penalidades de los delitos concretos.

\section{LESIÓN DE LOS PRINCIPIOS DE LESIVIDAD Y PROPORCIONALIDAD}

La perspectiva de género no impone la eliminación de los principios de lesividad y proporcionalidad. No son vestigios androcéntricos ni desprotectores. No debe darse la misma respuesta a supuestos en los que el medio empleado sea distinto. Quienes promueven la reforma no explican convincentemente de qué manera la protección del bien jurídico y del principio normativo de igualdad se refuerzan más mediante tal equiparación, si bien sostienen que la vigente regulación da lugar a interpretaciones jurisprudenciales dispares, fundamentalmente en los casos de agresiones en grupo, lo que debe ser evitado mediante fórmulas legales más claras.

El debate tiene una vertiente lingüística que no debe ser pasado por alto. Se defiende que el término "abuso" no capta el desvalor de la conducta y se presta a interpretar que el cuerpo de la mujer puede ser objeto de uso, aun indebido, por lo que todos los atentados contra la libertad sexual deben recibir la misma denominación: agresión. La utilización de un mismo nombre para referirse a todas las modalidades de ataque contra la libertad sexual puede tener un aspecto positivo, en cuanto que acomoda la denominación de los ataques sexuales a la gravedad que la ciudadanía percibe en muchos supuestos de los hasta ahora denominados abusos sexuales. Ahora bien, no debemos obviar que el recurso al mismo término (especialmente si éste es «agresión sexual»), puede producir efectos estigmatizadores ante la opinión pública y perjudicar las posibilidades de reinserción social, pues toda persona condenada por un delito sexual tendrá la consideración de agresor sexual aun cuando la conducta en el caso concreto haya podido ser menos grave (v.gr un tocamiento furtivo). Que existe este riesgo se demuestra constatando la carga que ha adquirido el término «maltratador» en el ámbito de la violencia en las relaciones de pareja, tanto al varón que de forma habitual agrede física y psíquicamente a su pareja para mantener una posición dominante en el marco de la relación como al que en un momento puntual y único ha propinado un empujón leve a la pareja en el contexto de una discusión.

Hechas tales prevenciones, en lo sucesivo utilizaré el término agresión, por el que se decanta el PLO, para poner de relieve que la equiparación encubre otros problemas más allá del lingüístico. Partiendo de tal denominación, el análisis de la regulación vigente, limitada a los delitos sobre adultos, evidencia 
que hoy día tenemos dos modalidades. Cada grupo lleva asociado los mismos marcos penales, estando más castigadas las conductas del primer grupo.

a. Agresiones de grado 1. En ellas, se emplea violencia o intimidación para doblegar la voluntad de la víctima. Para ello, hay que analizar si fueron idóneas para lograr el objetivo atendidas las circunstancias del caso (edad, vulnerabilidad de la víctima, etc.).

b. Agresiones de grado 2. Esta modalidad comprende varios supuestos. En primer lugar, el prevalimiento, que no constituye una violencia o intimidación de menor intensidad, sino el aprovechamiento por parte del agresor de su posición de superioridad para interferir en el proceso de formación de la voluntad de la víctima hasta lograr que se acomode a sus deseos. En segundo lugar, la agresión sobre persona privada de sentido. En tercer lugar, la agresión mediante la anulación de la voluntad de la víctima mediante el uso de fármacos, drogas o cualquier otra sustancia natural o química idónea. Por último, la agresión en la que hay una simple falta de consentimiento sin concurrir ninguna otra circunstancia.

La equiparación de todos los supuestos plantea diversos problemas:

a. Compromete los proporcionalidad y ofensividad, al equiparar conductas de distinta gravedad, incrementando el arbitrio judicial con paradójicos efectos de sobreprotección (el decisor puede optar por castigar la modalidad más leve en la extensión máxima) o infraprotección (el decisor puede optar por castigar la modalidad más grave en la extensión mínima). Es evidente que la violencia o la intimidación generan un daño superior, pero, además, es claro que tales medios comisivos suponen una mayor fuente de peligro, lo que debería reflejar, tal y como viene sucediendo, la regulación.

b. Desde el punto de vista criminológico, al sancionar todas las conductas con la misma pena, se incentiva el recurso a los medios más graves, que aseguran en mayor medida el resultado y no implican pluspunición.

c. En cualquier caso, para graduar la pena dentro del marco legal, lo más probable es que quienes juzguen tengan que diferenciar entre supuestos en función de la modalidad de ataque al bien jurídico, por lo que el pretendido problema probatorio tampoco se erradicaría, y habríamos introducido a cambio una gran inseguridad jurídica.

Por último, y respecto del argumento de la disparidad jurisprudencial, nuevamente faltan los datos estadísticos. Frente a tal argumentación, cabe oponer que hoy está generalmente asumido por la jurisprudencia que 
pasividad no equivale a consentimiento, y que tampoco se consideran consentidas incluso algunas conductas activas de participación. Así, se han elaborado construcciones tales como la intimidación ambiental o la violencia permanente, cuando el acto sexual se produce en el contexto de la violencia de género o doméstica, o la mal llamada violencia emocional en el caso de menores ${ }^{9}$. No es riguroso hacer de la anécdota categoría.

\section{EL APROVECHAMIENTO DE PERSONA CON VOLUNTAD ANULADA}

Por otra parte, la propuesta introduce un nuevo supuesto de hecho: atentar contra la libertad sexual cuando la víctima tenga anulada por cualquier causa su voluntad. En perspectiva de género es acertado que el supuesto de anulación de voluntad cuando el autor ha hecho uso, normalmente, de tóxicos y fármacos, sea considerado como un caso de violencia, pues el mecanismo empleado es típicamente violento, por lo que debe dejar de ser agresión de grado 2 y convertirse en agresión de grado 1 . Ahora bien, la reforma no hace eso: pasa a considerar violento todo aprovechamiento de una persona que tenga la voluntad anulada, aun cuando no haya sido el agresor el agente de la anulación de la voluntad. Y, además, al considerar como modalidad agravada, siempre y en todo caso, el supuesto en el que el autor haya anulado la voluntad de la víctima suministrándole fármacos, drogas o cualquier otra sustancia natural o química idónea a tal efecto, acaba considerando, siempre y en todo caso, la sumisión química más grave que la violencia o la intimidación, lo que carece de lógica.

\section{LA SUPUESTA ELIMINACIÓN DEL PREVALIMIENTO}

Finalmente, el PLO suprime aparentemente el prevalimiento, sin duda influido por el modo en que fue resuelto en la instancia el caso de La Manada. Y ello, pese a que sigue siendo un supuesto cualitativamente distinto a la intimidación y, que, por tanto, merece seguir diferenciándose de él. Las dificultades que puede ofrecer en casos concretos la diferenciación entre la intimidación y el prevalimiento no justifican la supresión de la segunda figura, esencialmente distinta. No se trata de un problema normativo, pues ya hay base legal y jurisprudencial suficiente para distinguirlos. Lo complejo es aplicar los criterios normativos en los casos difíciles, aquéllos situados en la «zona gris». Pero

9 V.gr. el agresor amenaza a la menor agredida con que si cuenta lo que ha pasado deberá el primero será expulsado de casa por el juez, tendrá que separarse de la madre del segundo, quien sufrirá mucho, y les faltará el sustento para subsistir. 
eso es consustancial a la vaguedad inherente a todo enunciado normativo, donde siempre hay un núcleo duro de significado junto a un espacio de penumbra, y a la complejidad de interpretar la realidad que constituye el objeto regulativo. Hay una cierta ingenuidad positivista, alejada de la práctica judicial, en la pretensión de que la norma puede garantizar una aplicación unívoca a la infinita variedad de supuestos que ofrece la realidad. En todo caso, no se advierte el efecto desprotector cuando bajo la regulación vigente las diferencias penológicas, en los supuestos más graves de acceso carnal, no son considerables (art. 179 CP: prisión de 6 a 12 años para la agresión de grado 1, y 4 a 10 años para la agresión de grado 2).

Pero, además, el PLO no es consistente, pues de hecho mantiene la figura mediante una formulación más laxa, pues el articulado proyectado se refiere en el tipo básico a los supuestos de «abuso de situación de superioridad o vulnerabilidad» (art. 178.2 PLO) y mantiene el prevalimiento en el catálogo de agravaciones (art. 180.1.5 PLO) «cuando, para la ejecución del delito, la persona responsable se hubiera prevalido de una situación de convivencia o de una relación de superioridad o parentesco, por ser ascendiente, o hermano, por naturaleza o adopción, o afines, con la víctima».

\section{UN HITO MÁS EN LA SENDA DEL ENDURECIMIENTO DEL SISTEMA}

En línea con reformas precedentes, se constata un endurecimiento, aun sensiblemente inferior al que se ha producido tras otras reformas, en un sector del derecho penal ya sobredimensionado. Efectivamente, el PLO supone una reducción del límite máximo de algunas penas ${ }^{10}$, pero la propuesta ha de ser examinada globalmente. Así, hay una ampliación de figuras delictivas y agravamiento de penas (v.gr. arts. 172 ter, 173.4, 181.1. inciso segundo, 182, 184 o 187 entre otros); al equiparar las distintas modalidades de ataque a la libertad sexual es inevitable que las conductas menos graves (los antiguos abusos) experimenten un relevante incremento penológico, lo que resulta evidente cuando inevitablemente han de aplicarse en la mitad superior si concurre alguna circunstancia agravante; y, además, se introducen prohibiciones y deberes preceptivos en el marco de la suspensión (art. 83).

10 V.gr. los supuestos de hecho equivalentes a la vigente agresión sexual pasan de castigarse con pena máxima de cinco años a tener una sanción máxima de cuatro ańos. De todos modos, como era de esperar, el texto final remitido a las Cortes Generales ha matizado mucho el alcance de la propuesta inicial del AP. 
El AP introdujo una regla penitenciaria que comprometía la dignidad de las personas condenadas y agravaba las condiciones de la ejecución. En concreto, el redactado del art. 74 bis de la LOGP en la práctica condicionaba la concesión de permisos de salida al sometimiento a tratamientos farmacológicos inhibidores del deseo sexual. Afortunadamente, el PLO ha prescindido de esta propuesta, pese a lo cual sigue manteniendo el régimen penitenciario especial para los delincuentes sexuales. El mantenimiento de este régimen especial constituye, en todo caso, un extrańo compañero de viaje para el modelo de género explicativo de la violencia estructural contra las mujeres, ya que es fruto de la expansión del paradigma patológico-individual, que caracteriza a los delincuentes como criminales de tendencia, como enemigos sociales irrecuperables, en sintonía con una jurisprudencia creciente que empieza a hablar, sin rubor alguno, en los casos de delincuencia sexual, de "maldad intrínseca» ${ }^{11}$.

Por otra parte, es innegable que la introducción de un tipo atenuado puede aliviar la presión punitiva, pero la redacción es poco taxativa, lo que puede ser fuente de inseguridad jurídica. La «escasa entidad» puede captarse en el ámbito de los delitos contra la salud pública tomando como parámetros la cantidad de droga y el riesgo de difusión y lesión del bien jurídico, pero presenta más problemas bajo la fórmula de la «menor entidad» en un ámbito como el sexual, más abierto a los juicios morales y a los juicios de valor. Sería conveniente que se aclarase el referente de la menor entidad aludiendo al grado de lesión del bien jurídico, para evitar interpretaciones moralizantes que orbitaran sobre el tipo de acto sexual o el ánimo o propósito empírico del sujeto.

Pero, además, ha de tenerse en cuenta que, de prosperar la reforma proyectada, la reducción de los límites máximos de algunas de las penas habría de provocar la revisión de las condenas en las que se hubieran impuesto las penas máximas conforme a la regulación vigente. Así las cosas, teniendo en consideración los precedentes legislativos, es poco probable que un legislador, preocupado principalmente por el efecto comunicativo o simbólico de la norma, se exponga al desgaste mediático que supondría la excarcelación anticipada de personas condenas por delitos sexuales, fruto de la revisión de las condenas, por lo que, con toda seguridad, los límites máximos de las penas se incrementarán durante el trámite parlamentario.

11 Advirtiendo esta paradoja a propósito de la LO 1/2004, Laurenzo Copello (2007). Véase, como ejemplo, la reciente STS 454/2021, ponente Sr. Magro Servet, que describe la conducta del agresor sexual como denotativa de una «maldad intrínseca». 


\section{CONCLUSIONES}

Tras este examen, podemos establecer algunas conclusiones:

a) No hay argumentos sólidos que avalen la afirmación de que la regulación vigente de los delitos sexuales sea androcéntrica o carezca de perspectiva de género. Dejando a un lado la cuestión estrictamente lingüística (supresión del término abuso) y la conveniencia político criminal de considerar «violencia» la anulación de la voluntad mediante la sumisión química, no encuentro argumentos normativos o empíricos que permitan sustentar las tesis de que la regulación responde a una visión estereotípica o sexista de la víctima, de que genera un impacto diferenciado para las víctimas por razón de sexo (lo que nada tiene que ver con el dato de que las mujeres sean mayoritariamente víctimas de este tipo de delitos), y de que, frente a tal estado de cosas, la normativa proyectada garantiza mejor el derecho a la igualdad de las mujeres.

b) No podemos pedir al derecho penal más de lo que puede darnos. El derecho penal no sirve para recomponer situaciones estructurales de desigualdad, sino solo para reaccionar civilizadamente frente a concretas situaciones de violencia discriminatoria. Para ello sólo puede acudir a una herramienta rudimentaria: la pena. Ciertamente, tipificando las manifestaciones de la violencia de género que atentan contra los presupuestos de la convivencia social y satisfacen el test de los principios de protección (lesividad, fragmentariedad y subsidiariedad, fundamentalmente) se produce un efecto preventivo general indispensable para mantener esa convivencia. Pero, llegado cierto punto, una vez sancionadas penalmente las conductas y establecidas para ellas determinados umbrales de pena, poco puede hacer el CP por la igualdad.

c) La aplicación de la técnica de diferenciación normativa a la que recurrió la LO 1/2004, basada en la voluntad del legislador «de sancionar más unas agresiones que entiende que son más graves y más reprochables socialmente a partir del contexto relacional en el que se producen y a partir también de que tales conductas no son otra cosa...que el trasunto de una desigualdad en el ámbito de las relaciones de pareja de gravísimas consecuencias para quien de un modo constitucionalmente intolerable ostenta una posición subordinada» (STC 59/2008) mutatis mutandis podría encontrar respuesta en el ámbito de los delitos sexuales en el art. 22.4. ${ }^{\circ} \mathrm{CP}$. Con todo, dados los marcos penales vigentes, que ya han perdido el sentido de la proporción, podemos plantearnos, puesto que mayoritariamente son las mujeres las víctimas de estas figuras delictivas, si tal circunstancia no ha sido ya tomada en consideración por el legislador al establecer las penas. En otro caso, la desproporción puede ser extrema. 
Por tanto, si lo que se pretende es que se visualice la diferencia para combatir la discriminación, la mejor opción legislativa sería rebajar drásticamente todas las penas previstas para estos delitos, que se encuentran sobredimensionadas, para, a continuación, introducir agravaciones específicas por razón del género o recurrir a la agravante genérica. Pero entonces comprobamos que lo que preocupa es el efecto simbólico o comunicativo-pedagógico, con lo que constatamos el reducido margen que el derecho penal tiene en la lucha contra la discriminación.

d) Con ello no pretendo afirmar que todo esté bien, sino reorientar el debate. Siguen existiendo praxis aplicativas burocratizadas y estereotípicas. Pero éstas no tienen que ver con la norma sustantiva, sino con el diseño de las investigaciones y la eliminación de prejuicios institucionales no sólo sobre las víctimas, sino también sobre las personas encausadas.

Creo que los esfuerzos habrían de volcarse en la protocolización de investigaciones eficaces, realizadas con perspectiva de género, así como en el fomento de una cultura jurisdiccional que trate con respeto y dignidad a toda persona que intervenga en el proceso, y no prejuzgue el caso sobre la base de estereotipos sobre lo que tales personas son, hacen o debieran ser o hacer. No son los incrementos de penas ya muy elevadas, o las ampliaciones típicas, sino la prevención y, en particular las investigaciones eficaces, las que sirven para combatir, desde el punto de vista penal, los delitos sexuales. No es la amenaza de una pena severa, sino la altísima probabilidad de condena debido a buenas investigaciones, lo que provoca el efecto preventivo general.

Hoy día, los principales problemas que suelen plantear los delitos sexuales son de orden probatorio y procesal, no de calificación jurídica. Ahora bien, no son los objetos de prueba (las descripciones típicas) los que generan eventuales efectos de desprotección que comprometen la libertad sexual y perpetúan las relaciones de dominación, sino: a) la incompletud de los medios probatorios, debido a investigaciones defectuosas y rutinarias que se contentan con recibir declaración a las personas implicadas; b) las valoraciones que de esos medios puedan hacerse, basadas en figuras estereotípicas de víctimas y agresores ideales, y c) el indolente y descuidado tratamiento procesal a todas las personas que intervienen en el proceso penal, lo que habría de constituir el centro de la reflexión y de atención de los poderes públicos.

Recientemente se ha conocido la decisión ministerial de paralizar de hecho en esta legislatura la tramitación, en estado ya muy avanzado, del Anteproyecto de Ley de Enjuiciamiento Criminal de 2020, el tercer intento en la última década de modernizar nuestro ineficiente y arcaico modelo procesal instaurado en el siglo xIx. A tal efecto, se ha pretextado la necesidad de atender los intereses corporativos de la fiscalía. Desde luego, siempre es menos costosa la reforma de la ley penal sustantiva, esto es, la del lenguaje 
de la norma, que opera sobre el papel, que la del modelo procesal, que opera sobre la realidad material. Pero mientras la segunda no tenga lugar, por más reformas que se produzcan de la primera, los cambios se mantendrán en el espacio de lo simbólico, sin la menor incidencia sobre la realidad que se pretende transformar. Así, son del todo puntos insuficientes las tímidas propuestas procesales contenidas en el PLO (modificaciones de los arts. 13, 112, 681 y 709 Lecrim).

Bajo mi punto de vista son las cuestiones investigativas y procesales, y no otras, las deberían haber protagonizado el debate político. En ese debate habría de abordarse el estudio de otros aspectos vinculados tales como:

a. ¿Por qué los investigadores suelen conformarse con incorporar al expediente las declaraciones de las personas implicadas sin buscar otras fuentes de prueba que aporten elementos de corroboración?

b. ¿Puede ello tener alguna incidencia en las tasas de falsas absoluciones? ¿Cómo puede estimarse, si es que se puede, cuán alta es dicha tasa? ¿Y la de su reverso?

c. ¿Nuestro modelo legal de proceso combina adecuadamente la resolución imparcial de los conflictos y la realización eficaz de las políticas públicas en la lucha contra la delincuencia? ¿Debe reformarse el modelo de investigación impulsando un modelo integrado por equipos de policía y fiscales especializados, fiscales que pueden impartir instrucciones no sólo particulares sino también generales, bajo el control de jueces de garantía imparciales?

d. Nuestro modelo procesal ¿trata mal sólo a las víctimas o a todas las personas que intervienen en el proceso? ¿Qué tal trata a las personas acusadas? ¿Puede tener alguna incidencia en el trato que se dispensa el carácter burocratizado de un modelo en el que la principal preocupación de quienes como policías, fiscales y jueces participan sea liberarse de la última oleada de asuntos antes de la inevitable llegada de la siguiente marea?

e. ¿El proceso penal es un juego de suma cero en el que la ganancia o pérdida de la víctima se equilibra siempre con la ganancia o pérdida de la persona acusada?

f. Si la especialización en materias parece indispensable en los órganos investigativos por razones de eficacia, ¿es igualmente aconsejable en los de enjuiciamiento, o puede inducir sesgos cognitivos que pugnen con el derecho al juez imparcial?

g. ¿Puede la proliferación de especializaciones en los órganos de enjuiciamiento comprometer el principio de unidad jurisdiccional en una suerte de retorno al pasado modelo de fueros? 
h. ¿Qué tipo de conocimientos, teóricos y prácticos, han de reunir las personas expertas que deben formar a los operadores jurídicos en perspectiva de género? ¿Cómo cabe verificar su cualificación? ¿La tienen todos los formadores de los 1374 jueces que han superado los cursos de perspectiva de género organizados por el Consejo General del Poder Judicial en el año 2020?

Tal vez un PLO de ley menos «integral», alejado de la reforma penal sustantiva, habría sido la ocasión perfecta para abordar este tipo de cuestiones, que suelen pasarse por alto en del debate público. Un debate que siempre acaba siendo vampirizado por el derecho penal, ese personaje egocéntrico que en las sociedades neoliberales de la posmodernidad reclama para sí solo toda la atención.

\section{Bibliografía}

Acale, M. (2018). Tratamiento penal de la violencia sexual, la forma más primaria de violencia de género. En P. Faraldo Cabana y M. Acale Sánchez (dirs). La Manada. Un antes y un después en la regulación de los delitos sexuales en España (pp. 71-102). Valencia: Tirant lo Blanch.

Arduino, I. (2019). Mecanismos de simplificación alternativos al juicio y género en el proceso penal: redefinir la discusión desde la política criminal. En J. Di Corleto (comp.). Género y Justicia Penal (pp. 265-284). Buenos Aires: Didot.

Camarena Grau, S. (2021). Consentimiento y libertad en el Anteproyecto de Ley de Garantía de la Libertad Sexual. Boletín Comision Penal. Juezas y Jueces para la Democracia, 13, 39-46. Disponible en: https://bit.ly/3mKdcuz.

Comisión Penal de Juezas y Jueces para la Democracia. (2021). Comunicado de la Comisión de Penal de JJpD ante el proyecto de Ley Orgánica de Garantía Integral de Libertad Sexual. Juezas y Jueces para la Democracia, 16-2-2021. Disponible en: https://bit.ly/3o0KUeH.

Díez Ripollés, J. L. (2003). La racionalidad de las leyes penales. Madrid: Trotta.

- (2013). Rigorismo y reforma penal. Cuatro legislaturas homogéneas (19962011). Partes I y II. Boletín Criminológico, 19. Disponible en: https:// doi.org/10.24310/Boletin-criminologico.2013.v19i0.7973 y https://doi. org/10.24310/Boletin-criminologico.2013.v19i0.7975.

- (2019). Alegato contra un derecho penal sexual identitario. Revista Electrónica de Ciencia Penal y Criminología, 21. Disponible en https://dialnet.unirioja.es/ servlet/articulo?codigo $=6985654$.

Faraldo Cabana, P. (2018). Evolución del delito de violación en los códigos penales espańoles. Valoraciones doctrinales. En P. Faraldo Cabana y M. Acale Sánchez 
(dirs.). La Manada. Un antes y un después en la regulación de los delitos sexuales en España (pp. 31-65). Valencia: Tirant lo Blanch.

Grupo de Estudios de Política Criminal. (2021). Comunicado sobre la reforma de las agresiones y abusos sexuales. Grupo de Estudios de Politica Criminal, 17-2-2021. Disponible en: https://bit.ly/3nZnR43.

Laurenzo Copello, P. (2007). Violencia de género y derecho penal de excepción: entre el discurso de la resistencia y el victimismo punitivo. En M. N. San Miguel Bergareche (dir.). Algunas cuestiones prácticas y teóricas de la Ley Orgánica 1/2004 (pp. 16-46). Madrid: Consejo General del Poder Judicial.

Larrauri, E. (2007). Criminología crítica y violencia de género. Madrid: Trotta.

- (2008). Una crítica feminista al derecho penal. En E. Larrauri. Mujeres y sistema penal (pp. 19-40). Buenos Aires: Editorial B de F.

Malón Marco, A. (2020). La doctrina del consentimiento afirmativo. Madrid: Thomson Reuters Aranzadi.

Ramírez Ortiz, J. L. (2018). Sociedad en red, igualdad, proceso y derecho penal. Jueces para la Democracia, Información y Debate, 92, 11-25.

- (2019). Perspectiva de género, prueba y proceso penal: una reflexión critica. Valencia: Tirant lo Blanch.

Rueda Soriano, Y. (2021). El proceso como mal necesario: víctimas y victimarios. Jueces para la Democracia, 101, 21-30.

San Miguel Berbareche, M. N. (2018). Creer y probar. Viento Sur, 24-10-18. Disponible en: https://bit.ly/3bKPB6M.

Soto Navarro, S. (2005). La influencia de los medios en la percepción social de la delincuencia. Revista Electrónica de Ciencia Penal y Criminología, 7, 7-9. Disponible en: https://bit.ly/3oi6L1x.

- (2006). Delincuencia en la prensa. Boletín Criminológico, 12, 1-4. Disponible en: https://doi.org/10.24310/Boletin-criminologico.2006.v12i.8766.

Vivas Larruy, M. A. (2016). Enjuiciar con perspectiva de género. Perspectiva de género en Derecho penal. En M. P. Marín López (dir.). Impartición de justicia con perspectiva de género en los distintos órdenes jurisdiccionales (pp. 29-92). Madrid: Consejo General del Poder Judicial. 